108

\title{
コヒーレント・ドップラー・ライダーによる風観則の可視化データ解析
}

\author{
浅井和弘 ${ }^{+0}$ 、星 貴久 + 、十束 款 $^{+}\left(^{+}\right.$東北工大)
}

水谷耕平*、板部敏和* ("郵政省・通信総合研究所)

\section{Visualized data analisis for atmospheric wind measured by coherent doppler lidar}

Kazuhiro Asai, Takahisa Hoshi, Makoto Totuka, Kouhei Mizutani, and Toshikazu Itabe

\begin{abstract}
Coherent Doppler lidar provide important data for investigating turbulent transport and exchange processes in the lower troposphere with high vertical and time resolution.. TIT (Tohoku Institute of Technology) and CRL(Communication Research Laboratories) have been developing the $2-\mu \mathrm{m}$ coherent lidar system. In this paper, we discuss the conceptual design of lidar system and also the algorithm for data analysis in order to visualize wind data. current status of our coherent Doppler lidar.
\end{abstract}

Keywords: Earth environment, Remote sensing, Laser radar, Doppler lidar, Wind measurement

\section{1.はじめに}

地球規模での大気風分布観測は、気象予測の精度向 上や気象現象、気候変動機構の解明に大きく貢献する ことが期待される. Coherent Doppler Lidar (以下 CDL とする)は、風向・風速といった風に関する情報を遠隔 測定できるリモートセンシング技術であり、航空機や 衛星からの地球大気観測手段として注目されている。 1.2,3,7,8) CDL に上る地球大気観測が実用化されれば、 観測データの解析結果を利用しや寸い形で表示寸る 必要がある。：しかし CDL 林、送受信光学軸(Line of Sight：以下 LOS と寸る)に対可風心情報しか得る ことができないため、RHI (Range Height Indicator), PPI (Plane Position Indicator) 等で 2 次元表示され た解析結果から風の場を理解寸ることは困難である:

本文では、CDLによって得られた大気風の測定デー タのビジュアル化を目的に、RHI，PPI のそれぞれの 場合に対して風の場を与えた時の表示結果のモデリ ング方法について述べ、さらに風の3 次元べクトル表 示結果についても述べる:

\section{2.コヒーレント・ドップラー・ライダーの原理}

一般にどんなにきれいな大気中においてもエアロゾ ルは存在するため、大気中に照射されたレーザ光はエ アロゾルによってミ一散乱効果が生じる。この時エア ロゾルが風に乗って移動しているならば、散乱光の周 波数はドップラー効果によって送信周波数からシフ トされる。このドップラー効果によってシフトされた 周波数成分をドップラー周波数と呼び、ドップラーシ フト周波数を解析することに上り遠隔地に㧈ける風 の情報を得ることができる。この CDL システムの概念
図をFig. 1に示寸。

送信レーザ光の Oscillator は、周波数安定化され たCW マスターレーザと距離分解能趸持つ高出力のパ ルスレーザで構成されている。発振周波数 $F_{0}$ のマスタ 一レーザ光はビームスブリッターによって二方向に 分けられ、一方をへテロダイン検波のためのロー

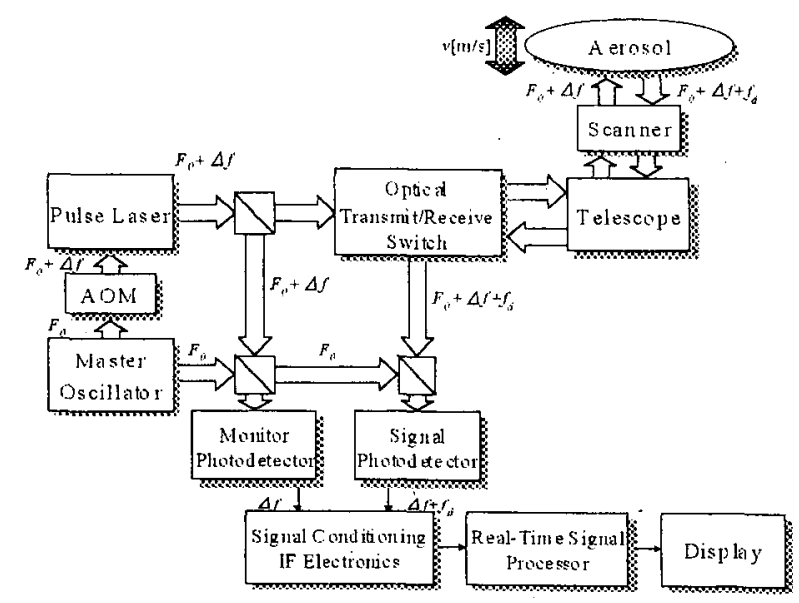

Fig. 1 Concept of Coherent Doppler Lidar (CDL)

カル光とし、残りを送信周波数安定化のためバルスレ ーザにシーディングされる。ここで負の周波数成分 (遠ざかる成分)を観測するため $\Delta f[\mathrm{~Hz}]$ のオフセット をか汁られバルスレーザ光は、望遠鏡を通し大気中 に照射され、エアロゾルによってミ一散乱効果を受け る。この時、ドップラー効果によってシフトされた周 波数成分 $f_{d}[\mathrm{~Hz}]$ と風速 $v[\mathrm{~m} / \mathrm{s}]$ の関係は以下の上うに 示寸ことができる。 


$$
v=f_{d} \lambda / 2
$$

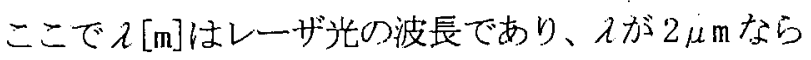
ば、=1[m/s]あたり $f_{\sigma}=1[\mathrm{MHz}]$ となることが分かる。

望遠鏡によって集光された散乱光は、光ミキサ一上 でマスターレーザ光と重祖合わされ、 $\Delta f+f_{d}$ (周波数 成分を持八電気信号に変換される。一方、オフセット 周波数は、バルスレーザ光とマスターレーザ光を Monitor Photodetector 上で重权合打せ $\Delta f$ の周波数 成分を持つ電気信号に変換される。さらに IF Electronics を通し Signal Processor で周波数解析 を行いDisplay に結果を表示させる。

\section{3. ドップラー周波数解析アルゴリズム}

得られた散乱受信信号からドップラーシフト周波 数を算出する周波数解析アルゴリズムとしては、 FFT (Fast Fourier Transform) やマイクロ波レーダの エコ一解析にも用いられているパルス対解析法など

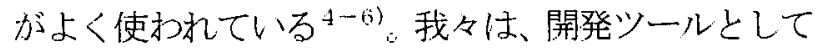
Borland C++、およびLab VIEW を用いFFT 周波数解析 法 (以下、FE: Frelquency Estimator と呼ぶ) につい て検討を行った。

実験には、米国コヒーレントテクノロジ一社製の2

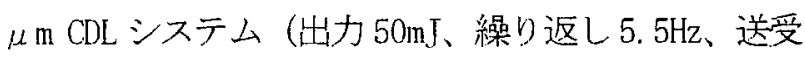
信光学系 $8 \mathrm{~cm} \phi$ 、最大測定可能距離 $6 \mathrm{Km}$ 、距離分解能 90in）を用いて行った。CDL によって得られたデータ は、Raw data fileとしてデジタルテープに一旦記録
され、実験終了後オフラインでドップラー周波数解析 功行われる。FFTを用いた Raw data file の解析アル ゴリズムをFig. 2に示す。

1Shot $の$ Raw data $は$ Monitor Signal (Binary, 8bit $\times 256)$ と Return Signal (Binary, 8bit × 16384) に分離 され、Monitor Signal 仿、八ニング空関数がが付ら れ256のサイズでFFTを行いオフセット周波数 $\left(f_{\text {offse }}\right)$ を算出する。観測では、1Shot ごとに送信レーザ光の

周波数に摇らぎが生じるため毎ショットごとに Monitor Signal の解析を行っている。一方、Return Signal は、16384 サンブルを64 サンブルずつ256の レンジに分割しハニング空関数をか忛、64のサイズ でFFTをか计る。そ心結果、各高度に対する受信信号 周波数 $\left(f_{\mathrm{d}}+f_{\mathrm{cofses}}\right)$ が求まる。このオフセット周波数 $\left(f_{\text {offse }}\right)$ と受信信号周波数 $\left(f_{d}+f_{\text {offse }}\right)$ の差をとることで、 Doppler shift frequency $\left(f_{d}\right)$ 算出し各高度に対卞 る風速を求める。更に、ショット平均を行うことで風 速測定精度を向上させている。

この FE ゙は、Raw Data File から 1Shot ごとにデ ータを読み込み、Monitor Data, Raw Data, Wind Velocity(1shot), Wind Velocity (Averaging shot) の波形を一画面で表示させる。この時の平均ショット 数はフロントパネルで選択でき、この解析では10Shot 平均を選択した結果を示している。この FEにより LOS 方向成分に怙ける風速を算出することが可能となる。

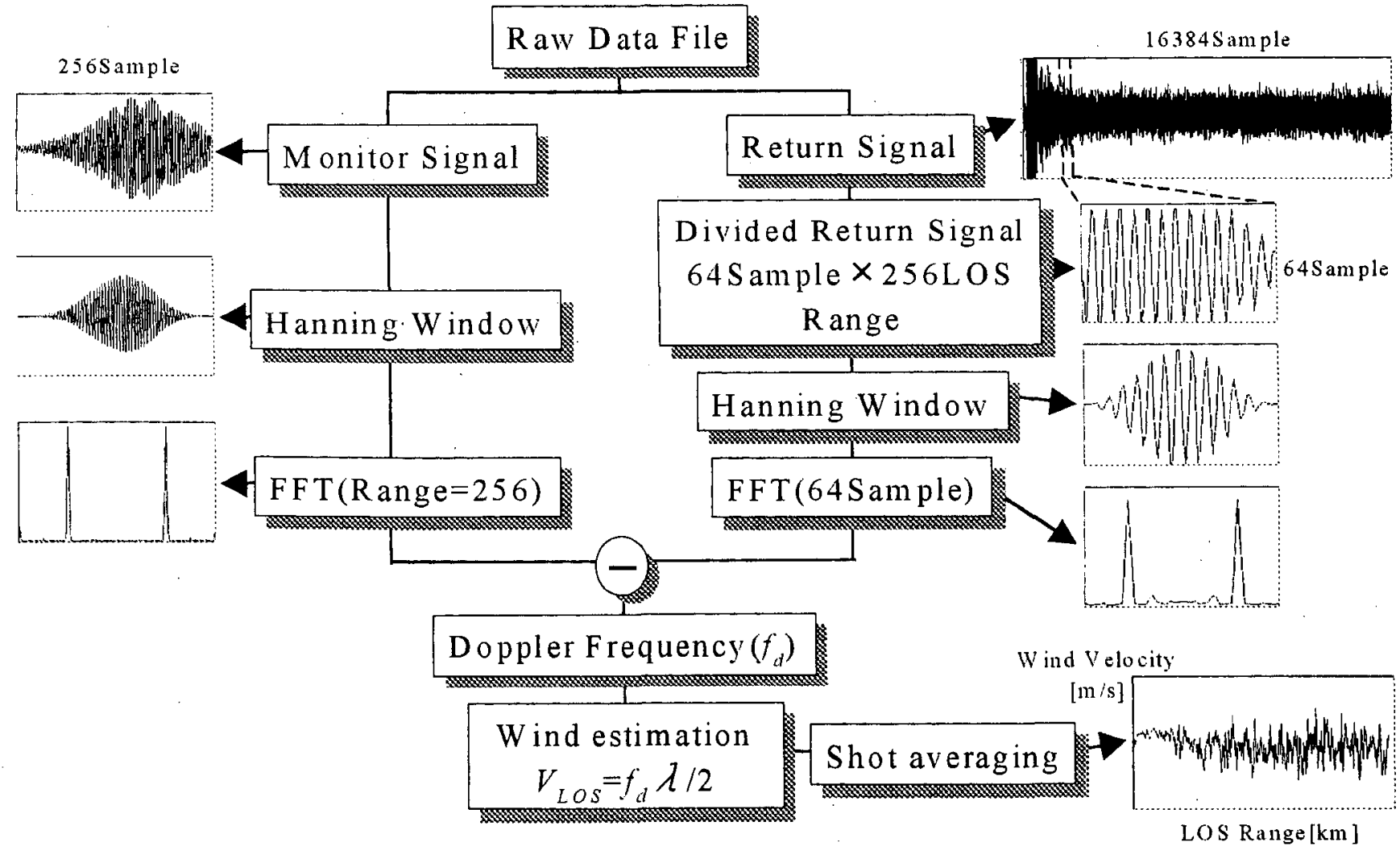

Fig.2 Algorithm for frequency estimator using FFT 
4. 観測データの可視化による大気風の場の推測 送受信光学軸に対する風の成分 $V_{\operatorname{Los}}$ と風の空間三成 分の関係式は

$$
V_{\text {LOS }}=u \sin \theta \cos \phi+v \cos \theta \cos \phi+w \sin \phi
$$

と表される。ここで、 $u[\mathrm{~m} / \mathrm{s}]$ は東西成分, $v[\mathrm{~m} / \mathrm{s}]$ は南 北成分, $w[\mathrm{~m} / \mathrm{s}]$ は風の鉛直情報成分であり、 $\theta[\mathrm{deg}]$ は北から時計方向にスキャニングさせた時の方位角, $\phi[\mathrm{deg}]$ は送信レーザ光の仰角である。(Fig. 3, 参照)

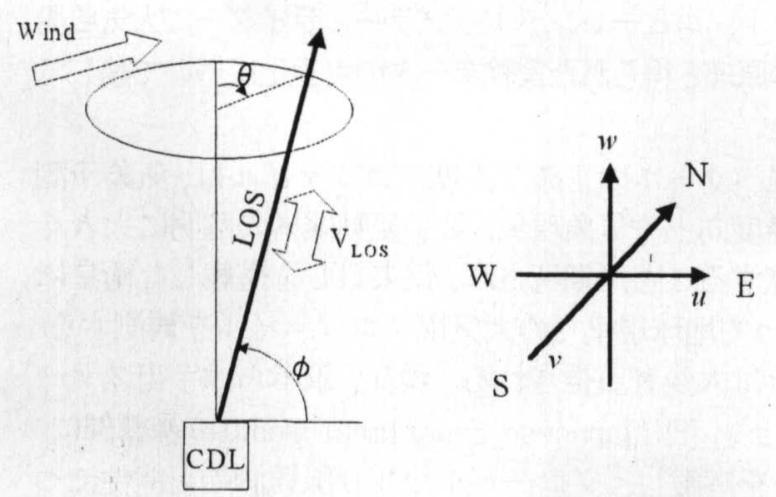

Fig. 3 Relation between optical axis and wind vector

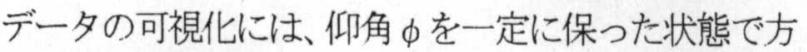
位角 $\theta$ を変化させ、変化に伴って得られる $\operatorname{LOS}$ 成分を 表示寸るPPI 法、方位角 $\theta$ を一定にして仰角を回転さ せて得られるLOS 成分を表示寸る RHI 法があり、以下 それぞれの可視化アルゴリズムについて明らかにす る。

\section{1) PPI 法}

一般的なPPI 表示法の概念図をFig. 4に、またFig. 5 に実験データをもとに我々が作成したPPI アルゴリ ズムを使って可視化した結果を示す。PPI は、各LOS レンジごとの平均風速をコンピュータのディスプレ イ上で2-D 表示寸る方法である。そのため、表示結果 から視覚的に風の場を推定することができない。

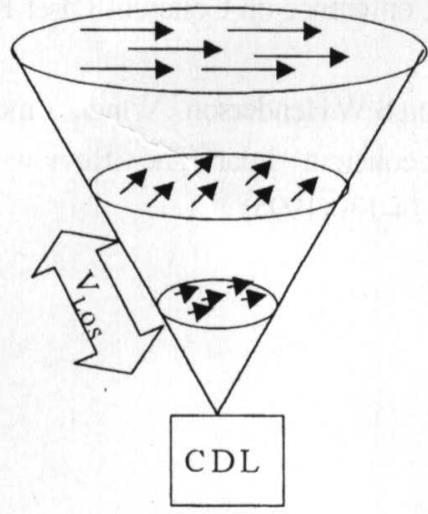

Fig. 4 Concept of PPI

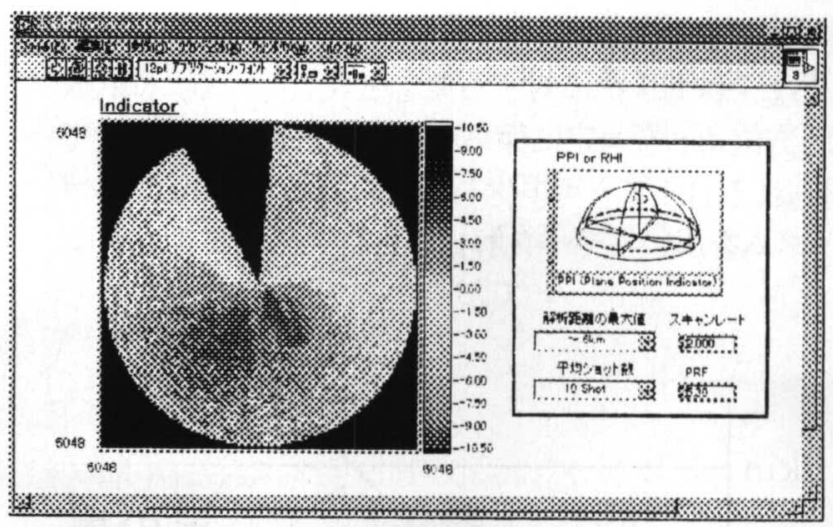

Fig. 5 Analyzed data using wi th algorithn for PPI

この観測では、Elevation を8[deg]と一定にし、 Azimuth を $52315[\mathrm{deg}]$ スキャンさせデータを取得し ている。Fig. 5 はLOSに対寸る風速を表示した結果で あるため、このPPI 表示結果から視覚的に風の場を推 定することは困難である。そこで各種表示法(RHI, PPI)に対し各レンジごとに風の場 $(u$ : 西から東へ吹く 風の成分, $V$ : 南から北に吹く風の成分, $w$ : 鉛直方向 の風の成分)を与え、表示結果のモデリングを行い各 LOS レンジに対する風の場を推定した。PPI における モデリング結果をFig.6に示す。

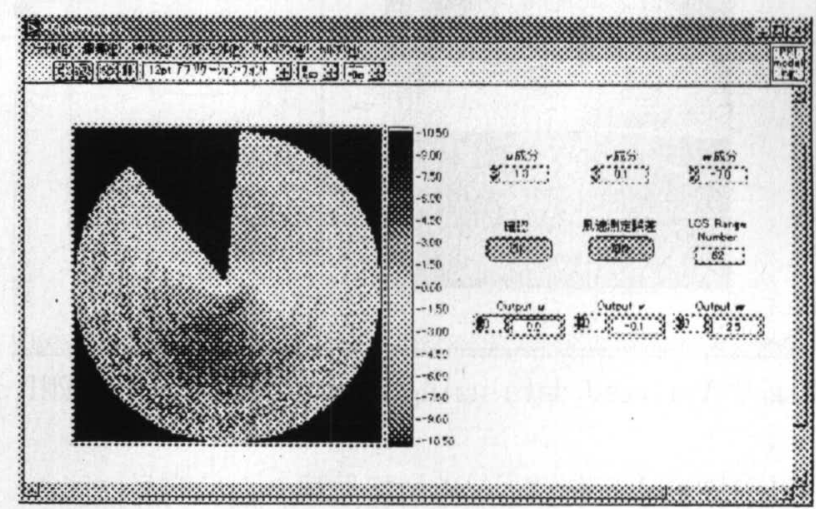

Fig. 6 Result obtained with modeling technique

PPI 観測データの解析結果Fig. 2 とモデリング結果 Fig. 3 を比較すると、表示結果がほぼ一致しているこ とから、PPI 観測時における風の場は、LOS レンジが 約 $1.5[\mathrm{~km}]$ (高度 $0.2[\mathrm{~km}]$ ) では $t F 1.0[\mathrm{~m} / \mathrm{s}]$, $v=5.5[\mathrm{~m} / \mathrm{s}], \|=2.7[\mathrm{~m} / \mathrm{s}]$ であり水平成分がほぼ北向 きで鉛直成分が上向きの風の場が推定できる。また、 LOS レンジが約 $3.0[\mathrm{~km}]$ (高度約 $0.4[\mathrm{~km}]$ ) では t $=1.7[\mathrm{~m} / \mathrm{s}], \quad v=5.3[\mathrm{~m} / \mathrm{s}], w=0.2[\mathrm{~m} / \mathrm{s}]$ であることから 水平成分が北北西向き、鉛直成分が上向きの風の場、 約 $4.5[\mathrm{~km}]$ (高度約 $0.6[\mathrm{~km}]$ ) では $u=0.5[\mathrm{~m} / \mathrm{s}]$, $v=3.3[\mathrm{~m} / \mathrm{s}], \|=4.9[\mathrm{~m} / \mathrm{s}]$ でることから水平成分が北 向き、鉛直成分が上向きの風の場が存在していること が推測される。 


\section{2) RHI 法}

Fig. 7 はRHI 法に対寸る概念を表している。RHI 法 は、方位角 $\theta$ を一定に保ちながら仰角 $\phi$ を変化させて 得られるLOS 值を可視化したものである。 RHI アルゴ リズムを用いてデータ解析した結果をFig. 8 に示し ておく。

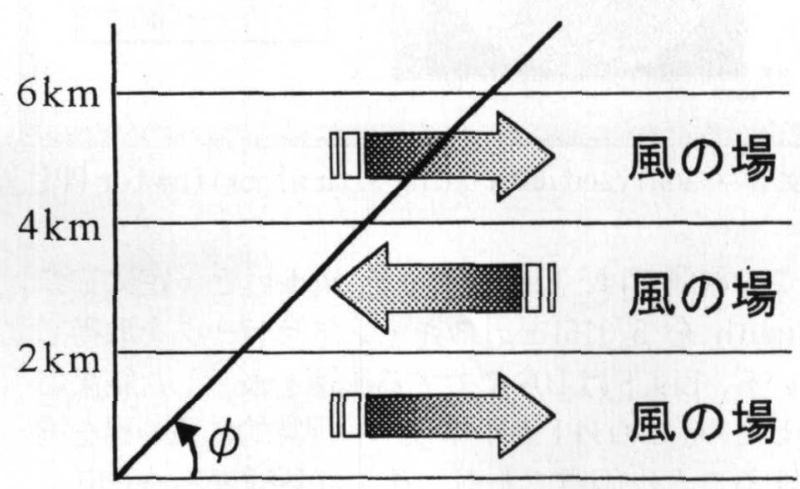

Fig. 7 Concept of RHI

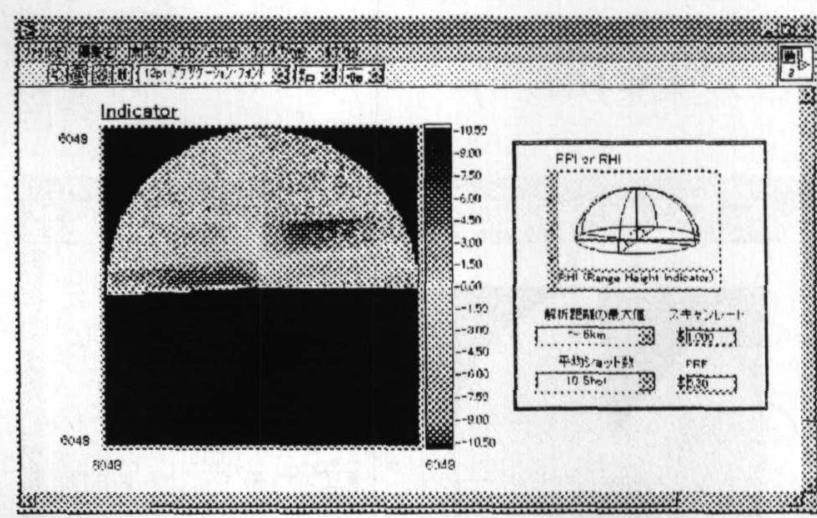

Fig. 8 Analyzed data using with algorithm for RHI

PPI 法の時と同様に、RHI 解析結果からは容易に風の 場を推測することは出来ないので、モデリングによる 実験データとの比較を行った結果を Fig. 9 に示寸。

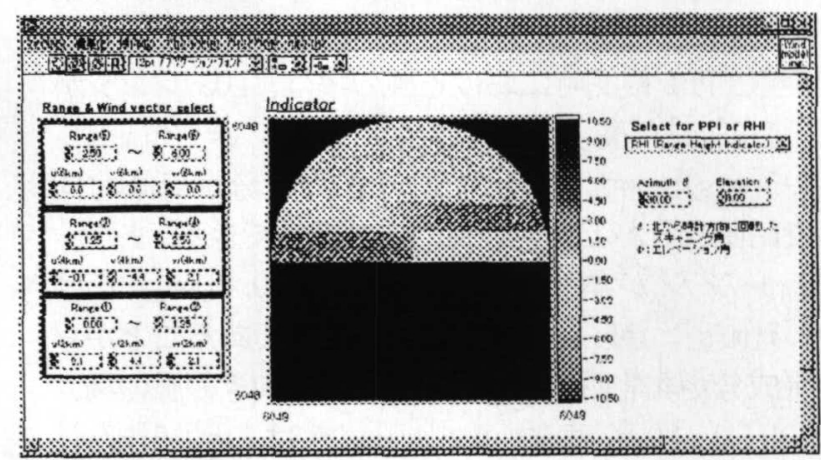

Fig. 9 Result obtained with modeling technique for RHI

モデリングでは、まず最大解析レンジを指定し、ある 高度での $u, v ， w$ コンポーネントを前述式に代入し、
風の光軸方向成分 $V_{L O S}$ 算出寸る。ここで、観測時に おける各高度に対寸る風速測定誤差を算出し、各高度 ごとのV $V_{\text {Lo }}$ に風速測定䛃差をかける。ここで得られた モデリング結果を Raw dataより算出した風の二次元 解析結果と比較し、視覚的に合致していれば次の高度 でのモデリングを行い、合致していなければ再び各コ ンポーネントを入力する。以上を最大レンジまで繰り 返し観測時におけるRHI のモデリングを行った。

\section{4.おおり}

以上、コヒーレントドップラー・ライダーに大気風測 定の原理と得られた実験データの可視化について論じて きた。

風ベクトルの正確な高度プロファイルは、気象予測 の精度向上や気象現象, 気候変動機構の解明に大きく 貢献することが期待され、将来CDL を搭載した衛星に よって地球規模での大気風プロファイルを観測する ことは大変有望視される。現在、筆者らは宇宙ステー ション JEM (Japanese Experiment Module) 暴露部に CDL を搭載し、グローバルな 3-D 風観測の可能性につ いての feasibility study（日本宇宙フォーラム・地 上公募研究フェーズII) を進めているところであり、 本研究はその一環として行われたものである。

\section{参考文献}

1) 浅井和弘, "大気循環,大気風の観測予測", 日本赤 外線学会誌, 第 3 巻, P.1-10(1993)"

2) ドップラーライダーによる宇宙からの風観測とデ 一タ利用に関する国内ワークショップ報告書”

3) Thomas J.Kane, Bingkun Zhou, and Robert L. Byer, "Potential for coherent Doppler wind velocity lidar using neodymium lasers", APPL.Opt. 23,2477-2481(1984)

4) 越川常治, “信号解析入門”, 近代科学社(1992)

5) 日野幹雄, “スペクトル解析”，朝倉書店(1997)

6) 青柳二郎，気象研究所技術報告書 第 19 号, P.733(1986)

7) J.Streicher,"Overview on signal processing for Doppler wind lidar", 9th Conference on Coherent Laser Radar, 118121(1997)

8) S.M.Hannon,S.W.Henderson,'Wind measurement applications of coherent lidar',The Review of Laser Engineering,23,124-130(1995) 